\title{
Lifestyle Practices and the Health Promoting Environment of Hospital Nurses.
}

Ann Hope, M.Sc., PhD.

Senior Researcher, Centre for Health Promotion Studies University College, Galway, Ireland

Cecily C Kelleher, MD FRCPI MPH MFPHM MFPHMI,

Professor of Health Promotion, Department of Health Promotion University College Galway, Ireland.

Maire O' Connor, MD MPH MRCPI MFPHMI,

Specialist in Public Health Medicine, Southern Eastern Health Board, Kilkenny, Ireland.

Address: Centre for Health Promotion Studies, University College Galway, Ireland 


\begin{abstract}
This paper examined the lifestyle practices of hospital nurses and the impact of specific interventions in the hospital environment. The perception of nurse as health promoter and as carer of AIDS patients was also examined. A self-administered questionnaire was used to collect data at two different time periods. The sample represented 729 nurses (at pre and post time periods), both qualified and student nurses. Qualified nurses reported the highest stress levels while student nurses reported more negative lifestyle practices such as smoking, alcohol consumption and drug use. A greater number of current smokers (29\%) consumed alcohol and used drugs than nonsmokers. The impact of intervention strategies around compliance with smoking policy and worksite walk routes reduced exposure to passive smoking at work for qualified nurses and increased exercise participation for both groups of nurses . Workplace was identified as the main source of stress which included relationships at work and demands of the job. Hospital nurses experiencing high workstress were more likely to use professional support and personal coping (discuss problems with friends/family, have a good cry and eat more) than others. Nurses believed in the importance of health promotion as part of their work, however, qualified nurses felt more confident and gave more health related information than student nurses. Student nurses perceived a lower risk of contacting AIDS through work and a higher concern/worry in caring for AJDS patients than qualified nurses.
\end{abstract}

\title{
Key Words
}

nurses, lifestyle practices, stress, health promoter 


\section{INTRODUCTION}

The evolution of health education and promotion over the last three decades has provided the catalyst for change and a framework for action towards improving the health and quality of life of all people. The health promotion actions of developing personal skills, creating supportive environments and a reorientation of the health services, community participation and healthy public policy, as outlined in the Ottawa Charter in 1986, has created a positive climate for all health professionals to examine their role as agents of change. In Ireland the publication of the new health strategy (Department of Health 1994) outlines a health promotion model of health care and the importance of the nursing profession in this process. The nurse professional is a key player in promoting change at a personal level, as role model, as health promoter and as professional carer.

The lifestyle practices of nurses which impinge on a sense of well-being such as stress, smoking and illicit drug use can provide as indication of their personal commitment to health promotion. Such practices may also reflect their personal work stress or indeed their professional ethos. Student nurses, from a New York survey, were not considered good exemplars of favourable health practices where they tended to smoke at a higher rate $(31 \%)$ than other health professionals, had a low use of seat belts, irregular eating habits and reported some binge drinking behaviour (Dittmar et al 1989). Age appears to be a mediating factor in smoking prevalence among student nurses in that the older the age group the greater the number of smokers (Cartledge Rausch et al 1987).

In England the prevalence of cigarette smoking amongst student nurses was $36.4 \%$ in the 18-49 age range which was similar to that of the general population. (Booth \& Faulkner, 1986). Most of those who did smoke had started the habit prior to their training. Just over half (57\%) of all current smokers reported that they wanted to 
stop. The support systems identified by current smokers as helpful in quitting were encouragement from other smokers trying to stop, help with cessation techniques, and received support from family, friends and colleagues. Weight control was perceived as a barrier to smoking cessation for many of the nurses.

When health behaviours of registered nurses and women from the general population were compared, no difference emerged in relation to exercise, smoking or excessive alcohol consumption, but nurses were overweight compared to the general population (Pratt et al 1994). The smoking prevalence among nurses was $8.7 \%$ and $15.8 \%$ in the general population; however in an income and education matched subset of the population the figure was only $6.1 \%$. The prevalence of smoking among qualified nurses, as reported in different studies, ranged from $8.7 \%$ to $19 \%$ (Pratt et al 1994; Stillman et al 1994; Speros \& Knack 1994). Nurses are reported to have a far higher prevalence of smokers than doctors (Stillman et al 1994). In an Irish context, a survey of lifestyle practices among qualified hospital nurses and public health nurses reported that public health nurses had a healthier lifestyle than their hospital based counterparts. The prevalence of smoking in the hospital nurses was $15.9 \%$ (Prendergast 1992). In another study, with a representative sample covering all nurse types, the smoking prevalence was $24.5 \%$ (Wynne et al 1993). A survey of the general population of Ireland reported $33 \%$ of those over 15 as current smokers however $36 \%$ in the $19-24$ age group, which would reflect the student nurse age category, and $40 \%$ in the $25-44$ age group were current smokers (Health Promotion Unit \& Dept of Education. 1996).

Although both doctors and nurses, within a hospital setting, agreed with a smoke-free environment, their attitudes differed towards the implementation and enforcement of smoking ban. Nurses were more tolerant and sympathetic toward smoking behaviours of others and more reluctant to enforce a ban on smoking (Stillman et al 1994). The complexities of introducing smoke free zones within a hospital setting have been highlighted with the conclusion that a smoke free hospital is an important part of an 
overall government anti-smoking strategy as it sends a clear message from health professionals of the risks associated with smoking (Philpot 1994). However, such policies must recognise that those implementing the smoking ban, mainly nurses, need educational skills to communicate with patients in order to avoid conflict situations which increases stress and compromise the nurse-patient relationship.

Traditionally, stress in the workplace has been seen as the responsibility of the individual worker in that programmes are focused on improving the individuals ability to cope with stress. However, more recent research has signalled the importance of stress in the context of the organisation where job tasks and job roles, patterns of communication and cultural norms are key factors in reducing worker stress (Kripke Byers, 1987). Stress in the nursing professional is widespread and the evidence suggests it is increasing in both its severity and impact (Farrington 1995, DionneProulx \& Pepin 1993, Wynne et al 1993). The workplace is a major source of stress for nurses which can include the nature of the work itself, the role of the nurse, career prospects and organisational structures. Developing resilience to stress through social support and coping strategies are believed to be of limited value unless elimination of stressors through organisational change is addressed concurrently (Dionne-Proulx \& Pepin 1993).

Qualified female nurses working in acute hospital settings in a region of Scotland reported workload as the most frequent stressful factor. The use of alcohol and illicit drugs were associated with stress. However concern about ADS was the single greatest predictor of total stress. There was no difference in stress level among smokers and non-smokers (Plant et al 1992). Other studies have shown that stress is a significant predictor of smoking status among women and smokers attributed work stress as a factor in their smoking behaviour (Sheahan \& Latimer, 1995). When a needs assessment was carried out in a hospital setting prior to the introduction of a 'Fit to Nurse' health promotion programme, stress was perceived as the highest risk with 
$75 \%$ reporting high levels of stress. Work was identified as the major source of stress followed by financial concerns and family matters (Speros \& Knack 1994). The Claybury stress study reported that psychiatric nurses working in the community mental health service had greater levels of stress than their ward-based counterparts. The top stressor for both groups related to inadequate resources, for the community nurse this was not having facilities to refer clients onto and for the ward nurse inadequate staffing cover in potentially dangerous situations (Fagin et al 1995). In a comprehensive study of stress amongst Irish nurses, non-hospital based nurses reported less stress and more job satisfaction than hospital based nurses. Stress from the home-work interface and the adequacy of social support were important factors in explaining mental well-being (Wynne et al 1993). Although social support plays an important role in promoting health, the mechanism by which its works is not fully understood (Minkler 1986). The use of social support as an effective strategy in coping with stress has been well demonstrated (Fagin et al 1995, Dionne-Proulx \& Pepin 1993, )

The vast majority of hospital nurses and public health nurses strongly agreed that health promotion should be an integral part of nurse training (Prendergast 1992). In reviewing the nurse as a health educator Clarke (1991) suggested that self awareness and personal development is more important than engaging in 'external healthy activities'. Building a relationship with the patient based on mutual respect and genuineness with effective learning methods is more creditable than a moralistic approach of giving advice. Developing self efficacy for health promotion activities during the educational process was shown to increase from first to final year student nurses which supports the inclusion of health promotion skills in the nurse education programme (Spence Laschinger 1996).

Health care of AIDS patients is now part of nursing care. A survey which examined nurses knowledge and attitude toward caring for AIDS patients revealed that there were gaps in nurses knowledge of AIDS and HIV infection. Although nurses were not 
extremely worried about AIDS in general, the more worried the nurse was about nursing an AIDS patient, the lower the intention to nurse the AIDS patient (Melby et al 1992). A qualitative study reported that nurses attitudes to AIDS patients varied and depended on social influences, personal experience and knowledge of HIV/AIDS. The majority of nurses interviewed stated they were apprehensive about nursing HIV positive patients (van Wissen \& Woodman 1994). The purpose of this paper is to examine the hospital sector with a specific focus on smoking and stress as key issues in both lifestyle practice and organisation impact. The nurse as health promoter and professional carer will also be explored.

\section{METHODS}

\section{Design}

This study was conducted as part of the Europe Against Cancer programme: Health Promotion in the Workplace. The overall aim was to design, implement and evaluate health promotion initiatives in the workplace. A cross-sectional survey was conducted across three different work sectors, industrial, educational and hospital at two different time periods, stage one and stage two.

\section{Sample}

The hospital sector was represented by qualified nurses (QN) and student nurses (SN) working and studying in an acute hospital setting. There were two data collection periods with a three year interval. At stage one (baseline) qualified nurses rostered for duty during a two week period were used as the study sample. The questionnaire was distributed to all those on duty and requested to complete and return to a designated collection point in each ward. The student nurses in attendance at lectures which represented the entire student population was the student nurse sample. The questionnaire was administered during a lecture slot for student nurses. At stage two 
(follow-up) the same criteria to select samples and the same procedures for data collection were used. The student nurses represented a new group of student nurses at stage two as those at baseline had completed their studies. The qualified nurses represented new staff, staff who were not on duty during stage one of the project and some who were involved in the original pre-intervention.

\section{Measures}

A self-administrated questionnaire was used to assess knowledge, beliefs, attitudes, lifestyle practices, availability of occupational health services along with job and organisational factors. Stress was measured incrementally using a 4-point scale from 'never' to 'very often'. The causes of stress and coping with stress were measures using a 3-point scale, never, sometimes and frequently. The importance of health promotion as part of their work was measured on a 4-point scale from 'very important' to 'unimportant'. The higher the score the greater the importance. The statement 'training in health promotion skills should be given more emphasis in the training of all health care professional' was scored from 4=strongly agree to $1=$ strongly disagree. Likelihood of getting AIDS through work and concern for caring with AIDS patients were measured on a 5-point scale. The higher the score the greater the perceived risk or concern.

\section{Analysis}

Descriptive and categorical data analysis using the software package SPSS $x$ was carried out. Statistical independence was tested by running chi-square tests on the selected variables. Student's t-tests were computed to test for difference between qualified nurses and student nurses on continuous variables. Analysis of covariance (ANCOVA) was used to test for differences between nurse groups (qualified and student nurse groups) and stage of project (stage one and stage two) on continuous variables with age as the covariate. 


\section{RESULTS}

Of those eligible from the hospital sector 729 nurses completed the questionnaire, 418 nurses at stage one and 311 nurses at stage two, which represented a response rate of $91.5 \%$ and $74 \%$ respectively. Demographic make-up of the respondents at stage one and two were similar. All of the qualified nurses and $97 \%$ of student nurses were female. The age profile showed the majority (97\%) of student nurses in the 18-24 age group and the majority (67\%) of qualified nurses in the 25-44 age group. Half of the qualified nurses and just $3 \%$ of student nurses were married.

\section{Lifestyle practices and the health promoting environment}

Table 1 reports the lifestyle practices and the health promoting environment of hospital nurses at stage one of the project. Overall a greater number of student nurses reported consuming a greater amount of alcohol, as reflected in their last drinking session, a greater number had tried illicit drugs in the last year and had a higher prevalence of current smokers than qualified nurses. A greate number of qualified nurses reported experiencing stress on a regular basis than student nurses. Exposure to passive smoking at work was reported more frequently $(p<.01)$ by qualified nurses than student nurses.

In the hospital sector the interventions were mainly designed to creating a supportive environment so that the healthier choice would be the easier choice. Compliance with the smoking policy regulations, a requirement under the national smoking regulations, was developed through a gradual process of change. Key senior workers were invited to declare their staff communal area smoke-free during peak breaks which then progressed to a smoke-free day and to the eventual declaration of the areas as smokefree. Walking routes were designed of varying distances $(5 \mathrm{mins}, 10 \mathrm{mins}$ and 15 mins) around the worksite. Colour coded routes were posted on staff notice boards. 
Stress was addressed by facilitating a forum (Time-out) for nurses to discuss issues related to work with the support of a facilitator.

At stage two, (post programme intervention) there was a significant $(p<.001)$ increase in the number of both qualified nurses $(+22 \%)$ and student nurses $(+13 \%)$ participating in regular exercise. A greater number of qualified nurses had increased their alcohol consumption $(+22.5 \%)$ and there was a decrease in qualified nurses reporting regular stress $(-11.7 \%)$, however there was no significant change in alcohol consumption or stress for student nurses. The prevalence of current smokers was similar at the two stages of testing. Exposure to passive smoking on a daily basis was significantly $(p<.05)$ reduced $(-12.6 \%)$ for qualified nurses as was exposure at work $(-25 \%)$. For student nurses there was no significant change in passive smoking exposure.

\section{Smoker Profile}

The data from the two stages of the project (smokers=212) were used to present a smokers profile which includes smoker's lifestyle practices, perceived supports and barriers to change in the smoking habit. The frequency of lifestyle practices of smokers and non-smokers revealed three significant differences $(p<.01)$ in relation to alcohol consumption, illicit drug use and eating patterns and with no significant $(p>.05)$ difference in stress or number of regular exercisers (Table 2). A significantly higher number of smokers reported consuming a greater amount of alcohol, as reflected in their last drinking session, and a greater number had tried illicit drugs in the last year. In comparison to smokers a greater number of non-smokers believed their current eating pattern to be healthy.

As already noted student nurses had a significantly $(p<.001)$ higher frequency of current smokers than qualified nurses. Of the hospital nurses who smoked, a significantly $(p<.01)$ greater number of student nurses $(21.3 \%)$ started smoking before 
the age of 14 in comparison to qualified nurses $(6.8 \%)$. There was no significant difference $(p>05)$ in the frequency of those smoking more than 15 cigarettes a day between nurse groups. A similar number (67\%) of current smokers among hospital nurses expressed the desire to quit smoking and (84\%) believed that their smoking level was harmful to their health. The top four ranked supports which qualified nurses identified that would be most helpful in assisting them to stop smoking were family/friends support, advice from a doctor, smoking cessation groups and restriction in pubic places. The student nurses ranked advice from a doctor as number one followed by smoking cessation group, family/friends support and restriction at work. For smokers who wished to quit, difficulty in breaking the habit, loss of enjoyment, a way of coping with stress and fear of weight gain were important factors which hindered both qualified nurses and student nurses from stopping smoking.

\section{Stress}

The extensive list of causes of stress and coping behaviours were reduced by factor analysis into a number of identifiable dimensions which were labelled to reflect the essence of each factor. The causes of stress were labelled work, lifestyle, family, worry/fear and loneliness (Figure 1). The coping mechanisms which individuals use when coping or trying to reduce stress were labelled medical coping, professional support, personal coping, negative behaviours and positive behaviours (Figure 1). New variables representing the different factors for sources of stress and coping behaviour were computed and became dependent variables in ANCOVA's where stage of project and nurse type were the independent variables with age as the covariate. The level of stress was also used as a dependent variable. The results of the statistical significant ANCOVA's with adjusted means and standards deviation are presented in Table 3. The top $F$ ratio for each variable reflects the stage of project effect (St). The second $\mathrm{F}$ ratio for each variable reflects the nurse type effect $(N)$. 
Qualified nurses had a significantly $(p<.05)$ higher level of stress than student nurses with no difference from stage one to stage two of project. Student nurses had a significantly $(p<.001)$ higher level of lifestyle stress due to lack of exercise and eating problems, and loneliness as a source of stress than qualified nurses. At stage one loneliness and worry due to fear of unemployment, bereavement and crime was a significantly $(p<.05)$ higher source of stress for hospital nurses than at stage two of the project. There was no significant difference $(p>.05)$ in work stress or family stress between qualified and student nurses. Student nurses used personal coping strategies, of having a good cry, eating more and discussing problems with close friends or family, to a significantly $(p<.05)$ greater extend than qualified nurses to reduce stress. There was no significant difference ( $p>05$ ) in medical coping, professional support, positive behaviours or negative behaviours as a means of coping with stress between qualified and student nurses or between stage one and stage two of the project.

To identify if differences in coping mechanism with workstress were evident workstress was dichotomised into high and low workstress using the mean score as the cut off point and was then used as an independent variable. The results of the ANCOVA's showed a significant difference in professional support and personal coping between high and low levels of workstress. Hospital nurses with high workstress used professional support (F, 11.68; $\mathrm{p}<.001)$ and personal coping $(\mathrm{F}$, $10.29 ; \mathrm{p}<.001)$ to a greater extend than those with low workstress. Factor analysis was computed on the perceived importance of issues surrounding their job which resulted in two main factors. Factor one was relationships in the job such as work colleagues, supervisors and management and promotional opportunities and this factor accounted for $39.3 \%$ of the variance. The second factor was financial security such as job security and pay accounted for an additional $21.2 \%$ of variance. The items in the two factors were computed to become dependent variables, similarly described in the previous factor analysis, and analysed by ANCOVA's across nurse type and stage of project controlling for age. At stage one of the project financial security (F, 7.54; 
$p<.01)$ was a significantly higher issue of perceived importance to the nurse's job than at stage two with no difference between nurse groups. There was no significant difference $(p>.05)$ in the importance of relations at work between nurse group or stage of project.

\section{Nurse as health promoter}

There was no significant difference $(p>.05)$ between qualified and student nurses who believed in the importance of health promotion as part of their work and also believed that training in health promotion skills should be given more emphasis in the training of all health care professionals (Table 6). A significantly $(p<.001)$ greater number of qualified nurses felt they were trained/qualified to give health promotion information than student nurses. Qualified nurses consciously availed of opportunities to give health related information as part of their clinical work to a significantly $(p<.001)$ greater extend than student nurses.

\section{Nurse as professional carer}

The belief and perceptions of hospital nurses in relation to professional care of high risk groups and health promotion are reported in Table 6. Chi-square and T-tests were calculated, where appropriate, to determine differences between qualified nurses and student nurses. The vast majority of both qualified and student nurses responded to questions on knowledge of risk factors and protective factors in HIV/AIDS correctly. Qualified nurses perceived the risk of the likelihood of getting the AIDS virus through their work as significantly $(p<.001)$ higher than student nurses. While student nurses had a significantly $(p<.001)$ greater concern/worry of caring for people who are HIV positive or who have AIDS beyond that they would have for a person with a chronic terminal illness than had qualified nurses.

\section{DISCUSSION}


A greater number of qualified nurses engaged in more positive behaviours and fewer negative behaviours than student nurses. Stress was the exception with qualified nurses reporting higher stress levels. Student nurses demonstrated more negative lifestyle practices such as smoking, alcohol consumption and drug use. Exposure to passive smoking affected the majority of qualified and student nurses both on a daily basis and at their place of work. The vast majority of hospital nurses reported job satisfaction.

The selected interventions were primarily passive strategies which included compliance with the smoking policy regulations, encouragement of exercise through walking routes and time-out discussion groups to address stress in the workplace. The impact of the intervention strategies showed fewer qualified nurses reporting regular stress, both groups exercised more and exposure to passive smoking was reduced for qualified nurses. However, when a more stringent analysis was conducted (ANCOVA) a reduction in stress levels was observed but it was not statistically significant.

When smokers were compared with non-smokers in lifestyle practices, a greater number of smokers tended to engage in other negative lifestyle behaviours such as alcohol consumption and drug use. Both groups reported similar levels of stress. Differences between qualified and student nurse smokers did emerge in relation to when they started to smoke and what supports they would find most helpful in quitting smoking. A greater number of student nurses started smoking before the age of 14 years with no difference in the number of current heavy smokers. Student nurses suggested advice from a doctor as the most helpful support while qualified nurses suggested family support. Both groups felt that smoking cessation groups would be the second most helpful support in quitting smoking.

The causes of stress for hospital nurses stemmed from a number of sources, work, lifestyle, family, worry/fear and loneliness. Student nurses perceived lifestyle stress 
(lack of exercise, eating problems) and loneliness as a greater source of stress than qualified nurses. At the beginning of the project loneliness and worry/fear (fear of unemployment, bereavement, crime) was a bigger source of stress than at stage two. The coping strategies that hospital nurses used to reduce and cope with stress included medical help, professional support; personal coping and engaging in negative or positive behaviours. Discussing problems with friends/family, having a good cry and eating more (personal coping) were more common for student nurses to engage in than qualified nurses. Those experiencing high workstress were more likely to use professional support (discuss with supervisor or health professional) and personal coping than those with low workstress. Hospital nurses perceived relationships at work and financial security as important issues surrounding their job.

Hospital nurses believed in the importance of health promotion as part of their work and also believed that health promotion skill training should be given more emphasis in their basic training. Qualified nurses felt more capable and subsequently gave more health related information than student nurses. The hospital nurses had a good knowledge of the HIV/AIDS risk factors and protective factors. The risk of contacting AIDS through work was perceived by qualified nurses to be higher than by student nurses. While student nurses had a higher concern of caring for HIV/AIDS patients.

It is important to remember when interpreting the results that the sample of nurses at the two testing stages of the project were for the most part independent groups. Therefore changes in lifestyle behaviours do not reflect a matched individual effect but rather a collective pattern of change over time. The baseline data provided for assessment of the hospital as a health promoting environment for workers. The interventions were designed to create a supportive environment conducive to change rather than active individual strategies alone. The findings would suggest a positive intervention benefit, both in terms of enhancement of the working environment by a 
reduction in exposure to passive smoking and positive lifestyle changes in exercise and stress. However since there was no control group caution should be used in interpreting the data. The positive impact on exposure to passive smoking for qualified nurses in the hospital setting did not influence the prevalence of smokers, however it did provide a healthier working environment for all workers. Daily exposure to passive smoking continued to be high for student nurses but exposure at work was relatively low. Given the nature of nurse training, with time divided between class room and workplace experience, opportunities for smoking at work are restricted which would suggest that much of their smoking was done outside their working/training environment.

The positive profile of qualified nurses and negative profile of student nurses in relation to lifestyle practices was supported (Pratt et al 1994, Stillman et al 1994, Speros \& Knack 1994, Dittmar et al 1989, Cartledge Rausch et al 1987, Booth \& Faulkner 1986). However the question must be posed, is the negative lifestyle profile of student nurses an inevitable life stage phenomena associated with college student behaviour or a more lasting pattern of damaging behaviours? Does it compromise their role as health promoter? An longitudinal study would be required to explore these issues.

The study findings did support the view that smokers were associated with more negative lifestyle practices than non-smokers (Cartledge Rausch et al 1987, Booth \& Faulkner 1986). However stress levels did not emerged as different between the groups. The earlier introduction to smoking for the student nurses would suggest an established habit by the time they decide to pursue nursing as a career and may explain the extent of heavy smokers among them. The number of heavy smokers amongst student nurses may also reflect the influence of their living conditions. First year student nurses were required to live-in during their training which might have encouraged more smoking among nurses due to peer pressure and lack of recreational 
activities. The desire to quit was substantial in both groups of nurses. However the strength of the perceived inhibitors such as stress and fear of weight gain does not provide an easy solution to possible changes in smoking behaviours but may provide a more realistic starting point for improvement in overall well-being. The interwoven complexity between stress, smoking and weight control is further demonstrated in the findings. Student nurses perceived eating problems as a source of stress but also identified eating more as a mechanism for coping with stress showing the cycle of negativity. Smoking and drinking was also used as ways of coping with stress.

Therefore developing health promoting skills of self-efficacy and personal development could enhance the health of the nurse as well as improve their ability to be a health promoter (Spencce Laschingfer 1996, Clarke 1991).

Stress is a major issue for nurses with the workplace having a large responsibility for the source of this stress (Carson et al 1995, Fagin et al 1995; Wynne et al 1993, Plant et al 1992 ). When issues perceived as important to the individual's working environment are not fulfilled, undermined or outside the direct control of the individual then it is more likely to become a source of stress (Dionne-Proulx \& Pepin 1993).

This study showed that nurses placed a high value on relationship at work as an important part of their working environment. However, the workplace was identified as the main source of stress and the causes of the workstress included relationships with colleagues, supervisors and management, the same issues important to their working environment. This would suggest that unresolved difficulties or conflicts did arise in these areas many of which could be described as organisational issues (Farrington 1995, Kripke Byers 1993). In coping with high workplace stress nurses tended to use professional support suggesting a positive mechanism of coping. However organisational issues of job tasks, patterns of communication, and cultural norms must also be addressed to reduce workplace stress (Kripke Byers 1993, DionneProulx \& Pepin 1993). The importance of stress from aspects of non-working life was also supported (Dionne-Proulx \& Pepin 1993). Given that the results represents two 
independent groups the higher stress stemming from worry and fear of unemployment and crime at stage one of the project may have reflected social and political issues of the day which in turn could have heightened individual concerns. The number of student nurses living away for home, perhaps for the first time, and the lack of an established social network may explain why loneliness changed in the two time periods.

Student nurses did not feel confident in providing health education with patients. This is understandable given that student nurses were in basic training and would have had little experience or opportunities in practising the health education skills with patients. Nurses had a good understanding of the general facts regarding risk and protective factors in HIV/AIDS. However, student nurses perceived a lower risk of contacting AIDS through work and a higher concern of caring for AIDS patients than experienced nurses This maybe because of an inadequate understanding of the nursing care for at risk groups and/or little experience with caring for these groups (van Wissen \&Woodman 1994). It may also reflect the strength of social and cultural norms which influences attitudes to subgroups of the population (Melby et al 1992).

In conclusion the findings of this study would suggest that health promoting skills should be integrated into nurse education. This could have a ripple effect at improving the personal health of the nurse and enhancing the nurse's role both as health promoter and professional carer. A strong social network developed for student nurses could provide an important mechanism for dealing with the challenges of a new career and the demands of college life. Organisational stress needs to be adequately addressed which will benefit the health of the individual worker and the health of the institution to ensure a health promoting hospital. 


\section{Acknowledgment}

This study was part funded by the Europe Against Cancer programme, Department of Health, Ireland and the Department of Health Promotion University College, Galway.

The authors wish to thank John Newell for his computing skills and Betty Delaney for her assistance in collecting the data. 


\section{References}

Booth K. \& Faulkner A. (1986). Links between nurses and cigarette smoking. Nurse Education Today, 6, 176-182.

Brown D., Bartlett H., Leary, J. \& Carson J. (1995). The Claybury community psychiatric nurse stress study: is it more stressful to work in hospital or the community? Journal of Advanced Nursing, 22, 347-358.

Cartledge Rausch J., Zimmerman G., Hopp J. \& Lee J. (1987). Smoking behaviour of student nurses enrolled in diploma, associate degree and undergraduate nursing programmes. Journal of Advanced Nursing, 12, 111-119.

Carson J., Leary J., de Villiers N., Fagin L. \& Radmall J. (1995). Stress in mental health nurses: comparison of ward and community staff. British Journal of Nursing, $4(10), 579-582$.

Clarke A.C. (1991). Nurses as role models and health educators. Journal of Advanced Nursing, 16, 1178-1184.

Department of Health (1994). Shaping a healthier future: A strategy for effective health care in the 1990s. Department of Health, Dublin, Government Publications.

Dionne-Proulx J. \& Pepin R. (1993). Stress management in the nursing profession. Journal of Nursing Management, 1, 75-81.

Dittmar S.S., Haughey B., O'Shea R.M. \& Brasure J. (1989). Health practices of nursing students: a survey. Health Values, 13(2), 24-31. 
Fagin L., Brown D., Bartlett H., Leary J. \& Carson J. (1995). The Claybury community psychiatric nurse stress study: is it more stressful to work in hospital or the community? Journal of Advanced Nursing, 22, 347-358.

Farrington A. (1995). Stress and nursing. British Journal of Nursing, 4(10), 574-578.

Health Promotion Unit \& Department of Education. (1996). A National Survey of Involvement in Sport and Physical Activity. Health Promotion Unit, Department of Health and Department of Education.

Kripke Byers S. (1987). Organisational stress: implications for health promotion managers. American Journal of Health Promotion, 2(1), 21-27.

Melby V., Boore J.R.P. \& Murray M. (1992). Acquired immunodeficiency syndrome: knowledge and attitudes of nurses in Northern Ireland. Journal of Advanced Nursing, 17, 1068-1077.

Minkler M. (1986). The social component of health. American Journal of Health Promotion, 4, 33-38.

Philpot T. (1994). The ethics of smoke-free zones: an exploration of the implications and effectiveness of a non-smoking policy as a health-promotion strategy in the context of an orthopaedic trauma ward. Journal of Clinical Nursing, 3, 307-311.

Plant M.L., Plant M.A. \& Foster J. (1992). Stress, alcohol, tobacco and illicit drug use amongst nurses: a Scottish study. Journal of Advanced Nursing, 17, 1057-1067.

Pratt J.P., Overfield T. \& Hilton H.G. (1994). Health behaviours of nurses and general population women. Health Values, 18(5), 41-46. 
Prendergast M.C. (1992). A study of attitudes, lifestyles and training in the context of health promotion and health and safety amongst nurses. Dissertation for degree of Master of Science in Occupational Health and Ergonomics. University College Galway, Ireland.

Sheahan S. \& Latimer M. (1995). Correlates of smoking, stress, and depression among women. Health Values, 19(1), 29-36.

Spence Laschinger H.K. (1996) Undergraduate nursing students' health promotion counselling self-efficacy. Journal of Advanced Nursing, 24, 36-41.

Speros C. \& Knack M. (1994) Fit to Nurse: A worksite health promotion program for nurses. American Joumal of Health Promotion, 8(6), 414-416, 424.

Stillman F.A., Hantula D.A. \& Swank R. (1994). Creating a smoke-free hospital: attitudes and smoking behaviours of nurses and physicians. American Journal of Health Promotion, 9(2), 108-114.

Van Wissen K. \& Woodman K. (1994). Nurses' attitudes concerns to HIV/ADíS: a focus group approach. Journal of Advanced Nursing, 20, 1141-1147.

Wynne R., Clarkin N. \& McNieve A. (1993). The experience of stress amongst Irish nurses - A survey of Irish Nurse Organisation members. Work Research Centre, Dublin, Ireland. 
Table 1

Lifestyle Practices \& Health Promoting Environment of Hospital Nurses at Stage One of Project $(\mathrm{N}=418)$

\begin{tabular}{|c|c|c|c|}
\hline & $\begin{array}{c}\text { Qualified } \\
\text { Nurses } \\
n=249\end{array}$ & $\begin{array}{c}\text { Student } \\
\text { Nurses } \\
n=169\end{array}$ & $\mathrm{p}^{*}$ \\
\hline $\begin{array}{l}\text { Regular Exercisers } \\
(3+\text { times per week) }\end{array}$ & $\begin{array}{c}\% \\
50.2\end{array}$ & $\begin{array}{c}\% \\
53.3\end{array}$ & ns \\
\hline $\begin{array}{l}\text { Eating healthy } \\
\text { (current belief) }\end{array}$ & 60.8 & 40.6 & $<.001$ \\
\hline Current Smokers & 25.5 & 34.1 & $<.001$ \\
\hline $\begin{array}{l}\text { Illicit Drug use } \\
\text { (past } 12 \text { months) }\end{array}$ & 1.7 & 17.6 & $<.001$ \\
\hline $\begin{array}{l}\text { Alcohol consumption } \\
\text { (7+ units last drink time) }\end{array}$ & 6.6 & 27.5 & $<.001$ \\
\hline Regular Stress & 39.1 & 19.6 & $<.001$ \\
\hline $\begin{array}{l}\text { Daily exposure to } \\
\text { passive smoking }\end{array}$ & 71.3 & 84.0 & $<.01$ \\
\hline $\begin{array}{l}\text { Exposed to passive } \\
\text { smoking at work }\end{array}$ & 71.7 & 56.6 & $<.01$ \\
\hline Job satisfaction (yes) & 85.3 & 84.1 & ns \\
\hline
\end{tabular}

${ }^{*}$ Chi-square statistic 
Table 2

Lifestyle Practices of Smokers and Non-smokers of Hospital Nurses $(\mathrm{N}=718)$

\begin{tabular}{|l|c|c|c|}
\hline & $\begin{array}{c}\text { Smokers } \\
\mathrm{n}=212\end{array}$ & $\begin{array}{c}\text { Non-smokers } \\
\mathrm{n}=506\end{array}$ & $\mathrm{p}^{*}$ \\
\hline $\begin{array}{l}\text { Regular Exercisers } \\
\text { (3+ times per week) }\end{array}$ & $\begin{array}{c}\% \\
\%\end{array}$ & $\begin{array}{c}\% 9.8 \\
\mathrm{~ns}\end{array}$ \\
\hline $\begin{array}{l}\text { Eating healthy } \\
\text { (current belief) }\end{array}$ & 43.9 & 55.4 & $<.01$ \\
\hline $\begin{array}{l}\text { Illicit Drug use } \\
\text { (past 12 months) }\end{array}$ & 16.6 & 4.4 & $<.001$ \\
\hline $\begin{array}{l}\text { Alcohol consumption } \\
\text { (7+ units last drink time) }\end{array}$ & 29.0 & 19.0 & $<.01$ \\
\hline Regular Stress & 29.0 & 28.0 & $\mathrm{~ns}$ \\
\hline
\end{tabular}

*Chi-square statistic 
Table 3

Factor Loadings on Sources of Stress

\begin{tabular}{|c|c|c|c|c|c|}
\hline Items & $\begin{array}{l}\text { Work } \\
\text { stress }\end{array}$ & $\begin{array}{l}\text { Lifestyle } \\
\text { stress }\end{array}$ & $\begin{array}{l}\text { Family } \\
\text { stress }\end{array}$ & Worry. & Lonely \\
\hline Relationship w mgt & .74 & & & & \\
\hline Job too demanding & .71 & & & & \\
\hline $\mathrm{R}$ w Supervisor & .70 & & & & \\
\hline Pressure at work & .66 & & & & \\
\hline Relationship w peers & .54 & & & & \\
\hline No self time & .54 & & & & \\
\hline Lack of exercise & & .80 & & & \\
\hline Eating problems & & .78 & & & \\
\hline Problems w spouse & & & .78 & & \\
\hline Family pressures & & & .72 & & \\
\hline Money worries & & & .53 & & \\
\hline $\begin{array}{l}\text { Fear of } \\
\text { unemployment }\end{array}$ & & & & .77 & \\
\hline Bereavement & & & & .57 & \\
\hline State of world/crime & & & & .57 & \\
\hline Loneliness & & & & & .72 \\
\hline Eigen Values & 3.64 & 1.62 & 1.24 & 1.21 & 1.04 \\
\hline Percent of variance & $24.3 \%$ & $10.8 \%$ & $8.3 \%$ & $8.0 \%$ & $7.0 \%$ \\
\hline
\end{tabular}

Total explained variance $58.3 \%$ 
Table 4

Factor Loadings on Coping with Stress

\begin{tabular}{|c|c|c|c|c|c|}
\hline Items & $\begin{array}{l}\text { Medical } \\
\text { coping }\end{array}$ & $\begin{array}{l}\text { Profession } \\
\text { al Support }\end{array}$ & $\begin{array}{c}\text { Personal } \\
\text { coping }\end{array}$ & $\begin{array}{l}\text { Negative } \\
\text { Beh. }\end{array}$ & $\begin{array}{l}\text { Positive } \\
\text { Beh. }\end{array}$ \\
\hline Take tablets & .77 & & & & \\
\hline Visit doctor & .76 & & & & \\
\hline Discuss w supervisor & & .74 & & & \\
\hline Discuss w HP outside & & .68 & & & \\
\hline Discuss w health pro. & & .66 & & & \\
\hline Good cry & & & .80 & & \\
\hline Eat more & & & .70 & & \\
\hline Discuss w friend/family & & & .65 & & \\
\hline Have a few drinks & & & & .79 & \\
\hline Have a cigarette & & & & .78 & \\
\hline Take some exercise & & & & & .74 \\
\hline Yoga & & & & & .74 \\
\hline Eigen Values & 2.27 & 1.56 & 1.49 & 1.14 & 1.05 \\
\hline Explained variance & $18.9 \%$ & $13.0 \%$ & $12.5 \%$ & $9.5 \%$ & $8.7 \%$ \\
\hline
\end{tabular}

Total Explained variance $62.6 \%$ 
Table 5

Stress, Sources of Stress and Coping with Stress

by Nurse Group over Life of Project

\begin{tabular}{|c|c|c|c|c|c|c|}
\hline & & ife of & roject & & & \\
\hline & Stag & One & Stag & wo & & \\
\hline & M & $\mathrm{SD}$ & $\mathrm{M}$ & $\mathrm{SD}$ & $\mathrm{F}^{*}$ & $\mathrm{p}$ \\
\hline Stress & & & & & $\mathrm{St}=3.27$ & .071 \\
\hline Qualified Nurse $(n=391)$ & 2.46 & 67 & 2.19 & .61 & $N=5.47$ & .020 \\
\hline Student Nurse $\quad(n=298)$ & 2.33 & .54 & 2.18 & .58 & & \\
\hline $\begin{array}{l}\text { Sources of Stress: } \\
\text { Lifestyle }\end{array}$ & & & & & $\mathrm{St}=3.33$ & .068 \\
\hline Qualified Nurse $(n=292)$ & 2.96 & 1.04 & 2.91 & .94 & $\mathrm{~N}=12.55$ & .000 \\
\hline Student Nurse $\quad(n=233)$ & 2.91 & 1.10 & 3.09 & 1.24 & & \\
\hline Worry & & & & & $\mathrm{St}=5.64$ & .018 \\
\hline Qualified Nurse $(n=276)$ & 4.69 & 1.21 & 4.68 & 1.06 & $N=0.62$ & .433 \\
\hline Student Nurse $\quad(n=220)$ & 4.80 & 1.32 & 4.27 & 1.02 & & \\
\hline Loneliness & & & & & $\mathrm{St}=4.29$ & .039 \\
\hline Qualified Nurse $(n=311)$ & 1.49 & 0.63 & 1.33 & 0.53 & $\mathrm{~N}=7.13$ & .008 \\
\hline Student Nurse $\quad(n=236)$ & 1.61 & 0.67 & 1.55 & 0.62 & & \\
\hline Coping with Stress: & & & & & & \\
\hline Personal Coping & & & & & $\mathrm{St}=0.02$ & .888 \\
\hline Qualified Nurse $(n=260)$ & 6.31 & 1.19 & 6.33 & 1.21 & $N=4.81$ & .029 \\
\hline Student Nurse $\quad(n=208)$ & 6.83 & 1.05 & 6.80 & 1.17 & & \\
\hline
\end{tabular}

*The top $\mathrm{F}$ ratio for each variable reflects the stage of project effect $(\mathrm{St})$. The second $F$ ratio for each variable reflects the nurse type effect $(N)$. 
Table 6

Nurse as health promoter and Professional Carer $(\mathrm{N}=729)$

\begin{tabular}{|l|c|c|c|}
\hline & $\begin{array}{c}\text { Qualified Nurses } \\
\mathrm{n}=428 \\
\text { Mean (SD) }\end{array}$ & $\begin{array}{c}\text { Student Nurses } \\
\mathrm{n}=301 \\
\text { Mean (SD) }\end{array}$ & $\mathrm{p}^{*}$ \\
\hline $\begin{array}{l}\text { Nurse as health } \\
\text { promoter } \\
\text { Importance of HP in your } \\
\text { work }\end{array}$ & $3.88(0.32)$ & $3.87(0.34)$ & $\mathrm{ns}$ \\
\hline $\begin{array}{l}\text { Give health related } \\
\text { information }\end{array}$ & $2.46(1.17)$ & $2.36(1.44)$ & $<.001$ \\
\hline $\begin{array}{l}\text { HP skills should be given } \\
\text { more emphasis in nurse } \\
\text { training }\end{array}$ & $3.84(1.01)$ & $3.72(1.06)$ & $\mathrm{ns}$ \\
\hline $\begin{array}{l}\text { Feel qualified/trained to } \\
\text { give health education }\end{array}$ & $77.1 \%$ & $47.1 \%$ & $<.001^{* *}$ \\
\hline $\begin{array}{l}\text { Nurse as professional } \\
\text { carer: } \\
\text { Knowledge of Risk: } \\
\text { - injecting drugs } \\
\text { - unprotected sex }\end{array}$ & 98.4 & & $\mathrm{~ns}$ \\
\hline $\begin{array}{l}\text { Knowledge of Protection } \\
\text { - reduce No. sex partners } \\
\text { - use condoms }\end{array}$ & 90.9 & 99.0 & $\mathrm{~ns}$ \\
\hline $\begin{array}{l}\text { Perceived risk of } \\
\text { AIDS through work }\end{array}$ & 96.4 & 93.6 & $\mathrm{~ns}$ \\
\hline $\begin{array}{l}\text { Concern/worry caring for } \\
\text { HIV/ADS patients }\end{array}$ & $2.54(1.51)$ & 96.0 & $\mathrm{~ns}$ \\
\hline
\end{tabular}

${ }^{*}$ T-test statistic **Chi-square statistic 